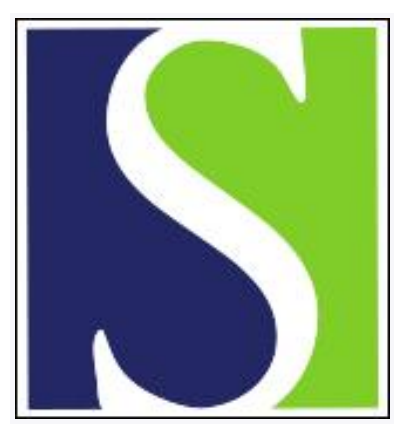

Scand J Work Environ Health 1999;25(6):610-615

https://doi.org/10.5271/sjweh.488

Issue date: Dec 1999

Towards the 24-hour society - new approaches for aging shift workers?

by Härmä MI, Ilmarinen JE

The following articles refer to this text: 2001;27(3):161-213;

2002;28(1):64-71; 2002;28(3):191-196; 2003;29(1):22-26;

2006;32(6):502-514; 2013;39(6):559-567; 2017;43(5):485-493

Key terms: circadian rhythm; countermeasures; occupational health; work schedule

This article in PubMed: www.ncbi.nlm.nih.gov/pubmed/10884161 


\title{
Towards the 24-hour society — new approaches for aging shift workers?
}

\author{
by Mikko I Härmä, MD, ${ }^{1}$ Juhani E IImarinen, $P h D^{1}$
}

\begin{abstract}
Härmä MI, IImarinen JE. Towards the 24-hour society - new approaches for aging shift workers? Scand J Work Environ Health 1999;25(6, special issue):610-615.

The new "24-hour society" increases night work and the diversity of flexible workhour patterns. At the same time, the number of older shift workers is growing in most developed countries due to the general aging of the working population. Together with new experimental and epidemiologic data on the alarming relationship of shift work to fatigue, performance, accidents, and chronic health effects like coronary heart disease, there is reason to believe that shift work may become a major occupational health and safety problem in the near future. The prevention of shiftwork-related health and safety problems will be a major challenge for the employer, employees, and occupational health professionals during the next few decades. The present paper shortly summarizes the current knowledge on the relationship between shift work, aging, and health and outlines practical countermeasures and research needs to improve the health and well-being of aging shift workers.
\end{abstract}

Key terms circadian rhythm, countermeasures, occupational health, work schedule.

The "24-hour society" has changed the timing of work profoundly. Globalization and changes in production and service needs have called for higher flexibility. The changing worker preferences in relation to individual timing of work, as well as the technological and structural changes in worklife, have all increased nontraditional worktime arrangements, the amount of night and shift work, and the complexity of worktime arrangements.

To give an example, the prevalence of worktime models other than regular day work increased from $24 \%$ to 30\% in Finland between 1984 and 1997 (1). The 2nd European survey on work conditions (2) (table 1) shows that working in shifts (including night work) decreases

Table 1. Prevalence (\%) of day and shift work among men and women $<45$ and $\geq 45$ years of age in the European Union (2).

\begin{tabular}{|c|c|c|c|c|}
\hline \multirow[t]{3}{*}{ Worktime arrangement } & \multicolumn{4}{|c|}{ Age } \\
\hline & \multicolumn{2}{|c|}{$<45$ years } & \multicolumn{2}{|c|}{$\geq 45$ years } \\
\hline & Men & Women & Men & Women \\
\hline $\begin{array}{l}\text { Regular day work } \\
\text { (no weekends) }\end{array}$ & 32.3 & 43.1 & 35.2 & 44.1 \\
\hline $\begin{array}{l}\text { Irregular day work } \\
\text { (often weekends) }\end{array}$ & 39.0 & 42.2 & 40.5 & 43.5 \\
\hline $\begin{array}{l}\text { Shift work } \\
1-4 \text { nights/month } \\
\geq 5 \text { nights/month }\end{array}$ & $\begin{array}{l}11.0 \\
17.7\end{array}$ & $\begin{array}{l}6.1 \\
8.7\end{array}$ & $\begin{array}{l}10.6 \\
13.8\end{array}$ & $\begin{array}{l}4.9 \\
7.4\end{array}$ \\
\hline
\end{tabular}

only slightly with aging: $24 \%$ of men and $12 \%$ of women over 45 years in Europe did shift work with night shifts.

It can be asked whether the trends in worktimes are also reflected in the health and well-being of aging workers. Strong evidence is scarce, and any epidemiologic attempt to separate worktime-related long-term effects on health from simultaneous changes in other work-related, psychosocial, or environmental factors is very difficult. However, according to a population-based survey on Finnish wage-earners, the prevalence rate of sleep problems increased from $25 \%$ to $35 \%$ from 1977 to 1997 (1). Poor sleep may be related to irregular worktimes but can also be a sign of psychological stress. In fact, the feeling of haste increased from $18 \%$ to $33 \%$ during the same time span, and the feeling of increased work pace went from $45 \%$ to $51 \%$.

The aging of the working population will be one of the largest structural changes to take place in the next 25 years. The proportion of the 50-to-64-year-old group of the whole working population (15-64 years of age) in the European Union will exceed $33 \%$ and, respectively, the 15-to-24-year-old population will fall to below $18 \%$ by the year 2025 (3). In Finland, the corresponding difference in the relative size between the oldest and youngest group of the work force will appear already before the year 2015. Global scenarios indicate that the

Reprint requests to: Dr Mikko Härmä, Finnish Institute of Occupational Health, Department of Physiology, Unit of Chronophysiology, Topeliuksenkatu 41 a A, FIN-00250 Helsinki, Finland. [E-mail: mikko.harma@occuphealth.fi] 
population over 60 years of age will increase from 120 to 250 million during the period $1980-2020$ (4).

The health of the older worker ( $\geq 45$ years of age) is affected by a biological aging process, by work, and by life-style. For example, according to a follow-up study of municipal employees aged 44-48 years, the proportion of employees with no diagnosed diseases decreased from $42 \%$ to only $16 \%$ during 11 years (5). The perceived work ability of the same study population declined during this period, and the decrease was more pronounced in physically than in mentally demanding work from the age of 51 to 58 years (6).

However, aging is also associated with mental growth, for example, in professional mastery, expertise, and improved strategic abilities (7). Therefore, aging at work can be characterized by both marked negative changes in health and positive changes in mental resources (8).

The expected trends for worktimes and aging during the next millennium call for new practical approaches for aging shift workers. The present paper briefly summarizes current knowledge on the relationship between shift work, aging, and health and outlines practical countermeasures and research needs to improve the health and well-being of aging shift workers.

\section{Aging, shift work and health}

\section{Circadian rhythms and sleep}

Most human functions, including physiological variables, sleep-wakefulness, and performance, follow a regular circadian rhythm. The peak activity associated with the circadian rhythm of most physiological functions occurs in the afternoon, while the circadian trough occurs normally during the early morning hours, between 0200 and 0600. The circadian trough in sleepiness during the night shift responds to the effect of moderate alcohol consumption (1.0\%o) (9) and has been shown to increase the risk for incidents and accidents in industrial operations and in rail, marine, aviation, and motor transportation (10).

Circadian adaptation to consecutive night shifts is slow - indicating an adjustment rate of only 1 hour a day (11). The adjustment rate depends most on the exposure to environmental light. In rapidly rotating shift schedules, which are the most frequent in Europe, it is practically impossible to synchronize circadian rhythms to the current sleep-wake schedule.

Aging has been found to decrease the amplitude of many circadian rhythms and to increase the tendency towards internal desynchronization (12). Aging decreases the speed of circadian adaptation to night work $(13,14)$ and has a major impact on sleep, which is the most important health complaint of shift workers.
Shift workers more than 40 years of age have an increased risk of sleep disorders. For example, in a prospective study of over 12000 men 40-50 years of age (15), the prevalence of self-reported sleep complaints among the night shift workers varied from $22 \%$ to $36 \%$, the prevalence difference between nightshift workers and those who did not do night work increasing during the follow-up of 5 years from $6.2 \%$ to $13.3 \%$.

The age-related changes in sleep are mostly related to curtailment of day sleep after night shifts. In a field study with actigraphic and sleep diary methods, shift workers over 40 years of age obtained consistently less sleep than younger shift workers, but morningshift sleep was similar in both age groups (16). It is a matter of interest that older workers rated their tiredness in the morning shift even lower than the younger group did, while there were no differences in the night shifts. The interactions found between aging and sleep in relation to different shifts fit well with the fact that aging is connected to increased "morningness" - meaning an advanced circadian rhythm of sleep-wakefulness and activity (17).

\section{Gastrointestinal disorders}

Research on the long-term health effects of shift work is increasing. The incidence of peptic ulcer has been calculated to be from 2 to 5 times higher among shift workers with night work than among day workers (18). In addition, as many as $20-75 \%$ of shift workers with night work (in comparison with $10-25 \%$ of day workers and shift workers without night work) complain of appetite disturbances, dyspepsia, abdominal pain, flatulence, and the like (19).

The few, already aging, epidemiologic studies on the relationship between shift work and gastrointestinal disease indicate that gastrointestinal problems are the most prevalent among young shift workers aged 21 to 25 years (20). The mean interval between the start of working in shifts and the diagnosis of peptic ulcer is short, only 5 years for rotating 3-shift workers and about 6 years for permanent night workers (21). If other digestive system diseases are included, the highest prevalence is found for shift workers with the longest work experience $(23-40$ years) (22)

\section{Cardiovascular disorders}

There is strong evidence that shift work is a significant risk factor for coronary heart disease (CHD). According to a recent review of 17 studies (23), shift workers seem to have about a $40 \%$ increase in CHD risk. Even if the relative risk is not high, the high prevalence of shift work itself yields a population etiologic fraction of more than $7 \%$ and makes shift work one of the major work-environment factors related to cardiovascular disease (24).

It is clear that the incidence of CHD increases with age. Knutsson and his co-workers (25) demonstrated a 
significant monotonic increase in CHD in association with increasing years of shiftwork exposure for the first 20 years of exposure. After the 1st 20 years, the risk fell to 0.4 , probably due to the selection of the cohort. From a practical point of view, it is important that shift work seems to trigger other, lifestyle-related risk factors of CHD. In a recent follow-up study of the joint effect of shift work and adverse life-style factors (26), shift work persistently accentuated the CHD risk associated with the effect of adverse life-style factors of smoking, sedentary life-style, and obesity, the joint effect being multiplicative.

\section{Psychoneurotic disorders}

Several studies have reported an increased number of psychosomatic complaints like chronic fatigue, nervousness, anxiety, sexual problems, and depression among shift workers (19). Recently, Scott and his co-workers (27) reported a pilot study showing an unexpectedly high prevalence of major depressive disorder among shift workers $40-65$ years of age. Like the incidence of CHD in the study of Knutsson and his collaborators (25), the prevalence of major depressive disorder seemed to in crease steadily among the elderly shift workers according to the length of exposure up to 20 years and thereafter decreased. The average prevalence was $15 \%$, but it increased to some $30 \%$ after $11-16$ years of shift work.

\section{Psychosocial health}

Working irregular hours has a major impact on leisuretime and domestic activities of all shift workers. The effects of shift work on leisure time are often both positive and negative. The same schedule provides such advantages as consecutive free days and such disadvantages as weekend work or occasional consecutive evening shifts interfering with social contacts.

Aging changes greatly the social and family situation of a shift worker. Since the housing and sleeping condi-

Table 2. Practical countermeasures to improve the health and well-being of older shift workers.

\begin{tabular}{ll}
\hline Sector & Countermeasure \\
\hline $\begin{array}{ll}\text { 1. Design of shiftwork } \\
\text { systems }\end{array}$ & $\begin{array}{l}\text { Increased flexibility for the worker } \\
\text { Increased time for recovery and workbreaks } \\
\text { Decreased amount of night work } \\
\text { - Reduction of the total amount of night work } \\
\text { - Redesign of the shift schedule } \\
\text { - Transferral of some night shifts to younger } \\
\text { shift workers } \\
\text {. Transferral of older night shift workers to } \\
\text { day work } \\
\text { Quickly rotating shift systems } \\
\text { Earlier shift-changing times in continuous shift } \\
\text { work } \\
\text { Intensified medical surveillance } \\
\text { Health counseling on appropriate coping } \\
\text { care } \\
\text { mechanisms } \\
\text { Individual solutions }\end{array}$ \\
\hline
\end{tabular}

tions often improve hand-in-hand with a worker's economic situation and domestic responsibilities decrease, the biological aging effects on health may be compensated by a favorable psychosocial situation. Older shift workers are also favored by the fact that they are practically self-selected and may have more experience with different coping mechanisms, such as priorities relating to sufficient recovery and napping, regular physical exercise, and so forth, with which to manage with shift work. Aging also changes a worker's value of leisure time. Although all workers, including shift workers, value the evening hours and weekends more than other periods of the day and week (28), shift workers of more than 45 years of age value free-time in the mornings during the weekdays, indicating a greater "morningness" in leisure-time activities, when compared with older shift workers.

\section{Practical countermeasures}

The health and well-being of the aging shift worker is a combination of several job-related, individual, and psychosocial factors (29). It is clear that the countermeasures should also be multiple, and they should involve multifaceted intervention focusing on all these factors. Although much research is needed to find and clarify the correct actions, it is possible to argue in favor of practical countermeasures based on current knowledge.

\section{Design of shiftwork systems}

Elderly employees have a need to adjust their work demands to their private lives. Aged shift workers have different needs for the duration, position, and distribution of daily, weekly, and yearly worktimes as compared with younger shift workers. In most cases it is difficult to achieve high flexibility for the company without granting some flexibility to the workers at the same time (30). Based on the individual needs of aging workers, increased flexibility for the worker (table 2) should be set as a general goal when worktime arrangements are improved.

Increased time for recovery by means of extra free days or workbreaks may be relevant to prevent negative health effects in the long run. It should be remembered, however, that many shift workers are inclined to accept extended worktimes and short intervals for successive work shifts in order to maximize the length of the day off period. Since the human brain cannot store sleep but needs it daily for full recovery, sufficient daily rest should be of primary biological interest. In other words, the interval of time-off between shifts and the sequences of similar shifts should allow adequate rest for older workers. The fact that older shift workers would benefit from 
an increased number of breaks during the work shift, to compensate for increased fatigue, should also be taken into consideration.

Sleep quality after night shifts is the major complaint of aging shift workers. On the other hand, older workers have fewer problems with morning shifts than younger shift workers. The effect of night shifts on elderly shift workers can probably be reduced by decreasing night work, for example, by reducing the total amount of night work through a redesign of the shift schedule (31) or the allocation of part of the night shifts to younger shift workers. The traditional shift schedules can be individualized by concentrating more morning shifts into crews with an older mean age and, correspondingly, by concentrating more night shifts into crews with a younger mean age.

Finally, the option of changing the older nightshift workers to day work should be considered on individual bases. Elderly shift workers face a special risk for the aggravation of the adverse health effects of shift work. If possible, shift workers aged $45-50$ years should be transferred to day work as a preventive measure $(32,33)$.

Because of longer spans of consecutive night shifts, older shift workers may have more problems adapting to slowly rotating shift systems. Middle-aged or older subjects may also be less sensitive to an acute sleep loss, as in the case of a single night shift (34). Thus quickly rotating shift systems should be favored in companies with many elderly workers. Since aging is related to "morningness" with the preference of earlier times of rising and retiring, earlier shift changing times in continuous shift work should be considered for older shift workers.

\section{Occupational health care}

There is general agreement that both medical surveillance and a counseling service for night shift workers is inevitable. It is also clear that intensified medical surveillance should be organized for aging shift workers with more health problems. The new European directive on the organization of worktime (93/104/EC) also states that "night workers are entitled to a free health assessment before their assignment and thereafter at regular intervals" [in article 9]. Medical health checks are necessary to detect the early signs of health problems related to shift work and to provide health counseling on individual coping mechanisms. Since aging is related to a steady increase in disorders of different origin, successive health checks should be planned within shorter periods for older workers $(19,35)$.

Appropriate coping mechanisms for both young and aging shift workers include the use of a correct sleepwakefulness rhythm and sleep hygiene, correct exposure to sun light or bright artificial light in relation to the used shift system, fatigue and stress management, sufficient physical activity during leisure time, correct eating and drinking habits, and the avoidance of drug and stimulant abuse.

There is not much evidence of older shift workers not benefiting from the same coping mechanisms as younger shift workers. According to a multiple sleep latency test (MSLT), older adults ( $30-80$ years of age) have a lower tendency for daytime sleepiness than young adults (18-29 years of age) do (36). The results could raise the question of whether older shift workers could similarly make use of work pauses for napping. The sleep and circadian rhythmicity of both young and older subjects have been shown to benefit similarly from physical activity (37). Middle-aged subjects may still be less phasetolerant to bright light than young subjects are (38), a question thus being raised concerning the utility of bright-light intervention in aging shift worker populations to promote the adjustment to consecutive night shifts.

Generally speaking, aging means a marked increase in individual differences in the physical, mental, and social sense. Therefore, the promotion of health and work ability of a heterogeneous older work force imposed to shift work should be based on appropriate individual solutions.

\section{Research needs}

There is a need for strong evidence on the possible relationship between shift work and chronic health. Especially the mechanisms by which shift work may be related to chronic diseases such as coronary heart disease, duodenal ulcer, spontaneous abortion, or even breast cancer are widely unknown (39). Whether the mechanisms are related to circadian "dysrhytmia", sleep deprivation, or psychological stress would be of primary interest when new shift schedules with different effects on circadian rhythms and sleep are designed and coping mechanisms relating to circadian adjustment (especially the use of "bright light" treatment to facilitate circadian adjustment) are selected.

The impact of increasing overtime and telework, and the interactions of extended worktimes and a faster work pace on health and well-being should be clarified. On the other hand, the relationship of well-established nightshift sleepiness on cognitive performance, productivity, and accidents in relation to different work demands should clearly be studied. It is not sufficient to study companyspecific changes in worktimes only with regard to psychosocial factors - changes in worktimes should be analyzed with an interdisciplinary approach by combining chronobiological, psychosocial, medical, and economic factors to get a comprehensive view of the change.

More applied research is needed to develop and test practical countermeasures to improve the health, safety, 
and well-being of older shift workers. There is a lack of research focusing on age-specific shift scheduling and new worktime models that try to increase flexibility for the aging worker with different levels of work ability, health, and social needs. During the beginning of the next millennium, more experimental studies are needed in new areas, such as information ergonomics, visual fatigue, and psychophysiological factors related to new information-intense tasks.

The aim should be to fit the new work demands of the current information society to the work ability of the aging work force by simultaneously developing the work environment, functional capacities, and various skills of the workers. We can expect good work ability and the health and competence of aging workers to be related not only to the quality of life, but also to improvements in productivity and the quality of work - and meaningful life after retirement (40).

\section{References}

1. Lehto A, Sutela H. Efficient, more efficient, exhausted. Helsinki: Statistics Finland, 1998. Labour market 12.

2. Paoli P. Second European survey on working conditions. Dublin: European Foundation for the Improvement of Living and Working Conditions Co, 1996.

3. Ilmarinen J. Ageing workers in the European Union - status and promotion of work ability, employability and employment. Helsinki: Finnish Institute of Occupational Health \& Ministry of Social Affairs and Health \& Ministry of Labour, 1999.

4. World Health Organization (WHO). Aging and working capacity. Geneva: WHO, 1993. Technical report series, no 835.

5. Seitsamo J, Klockars M. Aging and changes in health. Scand J Work Environ Health 1997;23 suppl 1:27-35.

6. Ilmarinen J, Tuomi K, Klockars $M$. Changes in the work ability of active employees over an 11-year period. Scand J Work Environ Health 1997;23 suppl 1:49-57.

7. Robertson A, Tracy CS. Health and productivity of older workers [review]. Scand J Work Environ Health 1998;24:8597.

8. Ilmarinen J. Aging and work - coping with strengths and weaknesses [editorial]. Scand J Work Environ Health 1997;23 suppl 1:3-5.

9. Dawson D, Reid K. Fatigue, alcohol and performance impairment. Nature 1997;388:235.

10. Dinges D. An overview of sleepiness and accidents. J Sleep Res 1995;4 suppl:4-14.

11. Minors DS, Waterhouse JM. Separating the endogenous and exogenous components of the circadian rhythm of body temperature during night work using some "purification" models. Ergonomics 1993;36:497-507.

12. Van Good WA, Mirmiran M. Aging and circadian rhythms. In: Gool WA, Van Haaren F, editors. Progress in brain research. New York (NY): Elsevier Science Publishers, 1986:255-77.

13. Härmä $\mathrm{M}$, Knauth $\mathrm{P}$, Ilmarinen J, Ollila $\mathrm{H}$. The relation of age to the adjustment of the circadian rhythms of oral temperature and sleepiness to shift work. Chronobiol Int 1990;7:227-33.

14. Härmä M, Hakola T, Åkerstedt T, Laitinen J. Age and adjustment to night work. Occup Environ Med 1994;51:568-73.

15. Moneta GB, Leclerch A, Chastang J, Tran T and Goldberg $M$. Time-trend of sleep disorder in relation to night work: a study of sequential 1-year prevalences within the GAZEL cohort. J Clin Epidiol 1996;49:1133-41.

16. Rosa R, Härmä M, Pulli M, Mulder M, Näsman O. Rescheduling a three-shift system at a steel rolling mill: effects of a 1hour delay of shift starting times on sleep and alertness in younger and older workers. Occup Environ Med 1996;53:677-85.

17. Åkerstedt T, Torsvall L. Shiftwork. Shift-dependent wellbeing and individual differences. Ergonomics 1981;24:26573.

18. Segawa K, Nakazava S, Tsukamoto $Y$, Kurita $\mathrm{Y}$, Goto H, Fukui A, et al. Peptic ulcer is prevalent among shift workers. Dig Dis Sci 1987;32:449-53.

19. Costa G. Effects on health and well-being. In: Colquhoun W, Costa G, Folkard S, Knauth P, editors. Shiftwork, problems and solutions. Frankfurt am Main (Germany): Peter Lang 1996:113-40.

20. Angersbach D, Knauth P, Loskant H, Karvonen MJ, Undeutsch K, et al. A retrospective cohort study comparing complaints and diseases in day and shift workers. Int Arch Occup Environ Health 1980;45:127-40.

21. Costa G, Apostoli P, Andrea F, Gaffuri E. Gastrointestinal and neurotic disorders in textile shift workers. In: Reinberg A, Vieux N, Andlauer P, editors. Night and shift work; biological and social aspects. Oxford: Pergamon Press, 1981:21521.

22. Koller M. Health risks related to shift work. Int Arch Occup Environ Health 1983;53:59-75.

23. Boggild H, Knutsson A. Shift work, risk factors and cardiovascular disease [reviews]. Scand J Work Environ Health 1999;25(2):85-99.

24. Akerstedt T, Knutsson A. Cardiovascular disease and shift work [editorial]. Scand J Work Environ Health 1997;23:241— 2.

25. Knutsson A, Åkerstedt T, Johnsson B, Orth-Gomer K. Increased risk of ischemic heart disease in shift workers. Lancet 1986:2:86-92.

26. Tenkanen L, Sjöblom T, Härmä M. Joint effect of shift work and adverse life-style factors on the risk of coronary heart disease. Scand J Work Environ Health 1998;24:351-7.

27. Scott AJ, Monk TH, Luann LB. Shiftwork as a risk factor for depression: a pilot study. Int J Occup Environ Health 1997;3 suppl 2:2-9.

28. Knauth P, Costa G. Psychosocial effects. In: Colquhoun P, Costa G, Folkard S, Knauth P. Shift work: problems and solutions. Frankfurt am Main (Germany): Peter Lang GmbH, 1996:89-112.

29. Härmä M. Sleepiness and shiftwork - individual differences. J Sleep Res 1995;4(2):57-61.

30. Knauth P. Innovative worktime arrangements. Scand J Work Environ Health 1998;24 suppl 3:13-17.

31. Knauth P, Eichhorn I, Löwenthal I, Gärtner KH, Rutenfranz J. Reduction of night work by re-designing of shift-rotas. Int Arch Occup Environ Health 1983;51:371—9.

32. International Labour Office. The hours we work: new work schedules in policy and practice. Cond Work Digest 1990;9(2).

33. Koller M. Occupational health services for shift and night workers. Appl Ergon 1996;27:31—7. 
34. Monk TH, Buysse DJ, Reynolds CF, Jarrett DB, Kupfer DJ. Rhythm vs homeostatic influences on mood, activation, and performance in young and old men. J Gerontol 1992;47:2217.

35. Koller M. Occupational health services for shift and night workers. Appl Ergon 1996;27:31-8.

36. Levine B, Roehrs T, Zorick F and Roth T. Daytime sleepiness in young adults. Sleep 1988;11:39 46.

37. Vitiello MV, Larsen LH, Moe KE, Prinz PN, Schwartz RS. The circadian temperature rhythm of healthy older adults is enhanced with improved aerobic fitness. J Sleep Res $1994 ; 2: 270$.
38. Campbell S. Effects of timed bright-light exposure on shiftwork adaptation in middle-aged subjects. Sleep 1995;18(6):408-16.

39. Härmä M. New work times are here - are we ready? [editorial]. Scand J Work Environ Health 1998;24 suppl 3:3-6.

40. Ilmarinen J, Huuhtanen P, Näsman O. Developing and testing models and concepts to promote work ability during ageing. In: Ilmarinen J, Louhevaara V, editors. FinnAge - respect for the aging: action programme to promote health, work ability and well-being of aging workers in 1990-96. Helsinki: Finnish Institute of Occupational Health, 1999:263-67. People and work, research reports 26. 